\title{
Autoconsciência e conversa interna de adultos obesos à espera de cirurgia bariátrica: Um estudo qualitativo
}

\author{
Petra Paim Ehrenbrink
}

Mariane Lima de Souza

\section{RESUMO}

O acompanhamento psicológico do obeso candidato à cirurgia bariátrica envolve uma avaliação da condição emocional deste paciente, especialmente com relação ao enfrentamento da ansiedade, pois ela terá impacto em sua recuperação e tratamento. Considerando que ansiedade possui relação com autoconsciência, o objetivo desse estudo foi descrever as características do processo reflexivo de obesos candidatos à cirurgia bariátrica, a partir de sua conversa interna. O estudo seguiu uma abordagem qualitativa, conforme os critérios da fenomenologiasemiótica. Participaram 10 obesos candidatos à cirurgia bariátrica com idades entre 31 e 65 anos, que responderam ao Protocolo de eliciamento de verbalização da conversa interna. Os resultados revelaram 12 temáticas da conversa interna: "Olhar-se no espelho", "Aceitação", "Ser diferente", "Vergonha", "Não sou o patinho feio", "Discriminação", "Crescimento pela dor", "Limitações e superação", "Mudança e resistência", "Pensar mais nos outros do que em si", "Opinião de terceiros", "Conceito de beleza". A discussão dos resultados pontua a importância que a posição do Outro adquire na conversa interna dos adultos obesos candidatos à cirurgia bariátrica, associada a uma perspectiva da própria posição como um lugar de diferença, e enfatiza o papel da conversa interna na autoconsciência.

Palavras-chaves: conversa interna; autoconsciência; obesidade; cirurgia bariátrica.

\section{ABSTRACT}

\section{Self-consciousness and inner speech in obese adults waiting for bariatric sur- gery: A qualitative study}

The psychological assessment of the obese candidate for bariatric surgery involves an evaluation of the emotional condition of this patient, especially with regard to coping with anxiety, since it will have an impact on his recovery and treatment. Considering that anxiety is associated with self-consciousness, the purpose of this study was to describe the characteristics of the self reflective process of obese candidates for bariatric surgery, considering their inner speech. The study followed a qualitative approach, according to the criteria of semiotic-phenomenology. The participants were 10 obese candidates for bariatric surgery aged between 31 and 65 years old, who responded to the Protocol of elicitation of verbalization of the inner speech. The results revealed 12 internal conversation themes: "Looking in the mirror", "Acceptance", "Being different", "Shame", "I'm not the ugly duckling", "Discrimination", "Growth through pain", "Limitations and overcoming, "Change and resistence", "Thinking about others rather than about myself", "Third-party opinion", "Beauty concept". The discussion of the results points to the importance that the Other's position assumes in the inner speech of obese adults who are candidates for bariatric surgery, associated with a perspective of one's position as a place of difference, and emphasizes the role of inner speech in self-consciousness.

Keywords: inner speech; self-consciousness; obesity; bariatric surgery.

A obesidade é uma doença que vem aumentando progressivamente e nos países em desenvolvimento sua evolução é ainda mais preocupante (Organização Mundial da Saúde OMS, 2016). Mudanças ao longo da história, que afetaram a forma como vivem as famílias es-

\section{Sobre os Autores}

P.P.E.

orcid.org/0000-0001-5079-4337

Samp Assistência Médica-

Vitória, ES

petra@samp.com.br

M.L.S.

orcid.org/0000-0002-7363-5926 Universidade Federal do Espírito Santo (UFES) - Vitória, ES limadesouza@gmail.com

\section{Direitos Autorais}

Este é um artigo de acesso aberto e pode ser reproduzido livremente, distribuído, transmitido ou modificado, por qualquer pessoa desde que usado sem fins comerciais. 0 trabalho é disponibilizado sob a licença Creative Commons CCBY-NC.






\section{MI* INTERACÃO EM LF PSICOLOGIA}

pecialmente em termos de produção e consumo da própria alimentação, têm um impacto no aumento do peso dos indivíduos, desde seus primeiros anos de vida (Moraes \& Dias, 2012). Conforme dados da OMS (2016), a obesidade mais que dobrou desde a década de 1980 no mundo e, em 2014, $39 \%$ dos adultos acima de 18 anos estavam acima do peso e $13 \%$ destes estavam obesos. Os gastos destinados à saúde em vários países do mundo abrangem, além dos custos médicos, um custo social decorrente do impacto da doença no modo de vida geral do obeso em áreas como o trabalho e a convivência social (Bahia \& Araújo, 2014).

Por outro lado, a ideia de que ter um corpo magro e saudável é sinônimo de sucesso e de que é do indivíduo a responsabilidade de estar ou não saudável colabora para o preconceito e gera pressão social para o emagrecimento. Essa situação gera sofrimento para o obeso, que já tem dificuldades em se enquadrar em uma sociedade que não é planejada para alguém com essa doença. Como consequência, a cirurgia bariátrica tem se tornado cada vez mais uma alternativa para que esses indivíduos possam se incluir nesses espaços (Moliner \& Rabuske, 2008).

Contudo, o tratamento cirúrgico exige uma intensa adesão dos pacientes no período pós-cirúrgico, que determinará mudanças de hábitos não somente alimentares, como comportamentais. A literatura científica descreve a existência de alterações psicopatológicas, ou de personalidade, como fatores que podem comprometer o tratamento (Travado, Pires, Martins, Ventura, \& Cunha, 2004), ainda que a obesidade não deva ser obrigatoriamente associada a problemas psicológicos (Oliveira \& Yoshida, 2009). É comum também que pacientes candidatos à cirurgia escondam a realidade de sua saúde psicológica, inibindo emoções negativas e subvalorizando-as, para serem logo aprovados para a cirurgia (Franques, 2002), como por exemplo, a depressão e a ansiedade (Cataneo, Carvalho \& Galindo, 2005).

A ansiedade, mais especificamente a ansiedade social, que é o desconforto que um indivíduo sente diante da presença de outros, já foi identificada como um dos três fatores relacionados ao processo de ficar atento sobre si ou, em outras palavras, de estabelecer autoconsciência (DaSilveira, DeSouza, \& Gomes, 2015). Isto é, embora não seja diretamente relacionada à forma como alguém toma a si próprio como objeto de seu pensamento, a ansiedade social tem relação com o grau de atenção com que a pessoa reflete sobre si. Neste sentido, compreender o processo autorreflexivo do candidato à cirurgia bariátrica pode lançar luz sobre as experiências emocionais vivenciadas por esse indivíduo.

Além disso, de uma perspectiva psicológica, o acompanhamento adequado e eficiente do obeso antes e após a cirurgia envolve certamente um entendimento da percepção que ele ou ela tem do mundo e, especialmente de si mesmo.
Em outros termos, a autoconsciência pode desempenhar um papel relevante em todo o processo psicológico experienciado por essa pessoa que está em busca de uma mudança de vida, quando se torna uma candidata à cirurgia bariátrica.

\section{AUTOCONSCIÊNCIA E CONVERSA INTERNA}

A investigação da autoconsciência, ainda que um tema seminal na história da psicologia como disciplina científica é ainda desafiadora, seja pelas dificuldades metodológicas que se impõem, seja pela própria dificuldade conceitual de definição do termo (Morin, 2017). A fala interna pode ser definida como aquela conversação que o indivíduo estabelece com ele mesmo, mentalmente, e é considerada fundamental para o estabelecimento da autoconsciência (Morin, 2012). Neste sentido, a fala interna ou conversa interna pode ser tomada como um indicador do processo autoconsciente (DaSilveira, DeSouza, \& Gomes, 2010).

De fato, quando se está pensando, a fala pode se manifestar enquanto uma conversa com nós mesmos, realizada de forma inaudível para um observador externo. Essa conversa interna desempenha um papel mediador entre o indivíduo e as informações que ele recebe do meio social (Archer, 2012).

A conversa interna tem sido definida, portanto, como o principal meio de articulação da autoconsciência (Morin, 2017), com impacto considerável na ação reflexiva (Motta, Rafalski, Rangel, \& Souza, 2013). O autoconhecimento, por sua vez, estaria relacionado à significação através da conversa interna que se utiliza dos signos herdados do mundo social e da cultura, e desempenha um papel de mediação entre o mundo externo e o interno. Por isso, a autoconsciência pode ser definida como um processo reflexivo da consciência, constituído enquanto uma conversação interna (DaSilveira, DeSouza, \& Gomes, 2010). A conversa interna permite ao indivíduo se tornar objeto de sua própria consciência, viabilizando, portanto, o autoconhecimento, a autorregulação, a autoestima, a identidade pessoal e o senso biográfico. Estimase que um quarto da atividade consciente seja composta pela conversa interna, que está diretamente relacionada com o processo de autoconsciência e de autorreflexão (Morin, 2012).

A investigação psicológica da conversa interna como via de acesso à reflexividade é, contudo, um desafio em termos metodológicos. Tem-se utilizado como método mais recorrentemente a autoverbalização (DaSilveira, DeSouza, \& Gomes, 2010). Além disso, os diários pessoais, as listas de compras e outras fontes similares de escrita privada, isto é, de escrita que as pessoas produzem para si mesmas têm sido utilizados como fonte de dados (Morin, 2012). Entretanto, um estudo alternativo propôs o uso de blogs (páginas na in- 


\section{H NTERAC̄OOEM ET. PSICOLOGIA}

ternet contendo relatos pessoais) como instrumento para pesquisar pensamentos e percepções conflitantes que as pessoas têm sobre si mesmas (Benites, Gauer, \& Gomes, 2016). A avaliação positiva desse procedimento pelos pesquisadores sugere que a exploração de fontes mais espontâneas de conversa interna e de outras técnicas que se assemelham a procedimentos que as pessoas já utilizam para registrar sua conversa interna pode ser efetiva na investigação do fenômeno.

Desta forma, o presente estudo teve como objetivo descrever o processo autorreflexivo consciente, isto é, a autoconsciência de indivíduos em processo de preparação para a realização da cirurgia bariátrica, a partir de sua conversa interna. Espera-se que a conversa interna verbalizada dos participantes apresente temáticas relacionadas à sua vivência enquanto obesos, bem como expresse uma percepção de si centrada em aspectos emocionais.

\section{MÉTODO}

Trata-se de um estudo exploratório com abordagem qualitativa e descritiva (Creswell \& Clark, 2013), conforme os critérios de análise da fenomenologia-semiótica (Gomes, 1998; Lanigan, 1992).

\section{PARTICIPANTES}

Participaram do estudo dez obesos adultos, com idades entre 31 e 65 anos, escolaridade mínima de ensino fundamental incompleto e profissões variadas, em processo de tratamento pré-cirurgia bariátrica, já com indicação de cirurgia e realizando acompanhamento psicológico (Tabela 1). Foi formada uma amostra por conveniência, seguindo o critério de saturação teórica, segundo o qual a coleta é encerrada quando os dados obtidos apresentam repetição ou redundância.

Tabela 1. Idade, Sexo, Escolaridade e Profissão dos Participantes

\begin{tabular}{ccccc}
\hline Participante & Idade & Sexo & Escolaridade & Profissão \\
\hline P01 & 52 anos & F & Ensino Fund. Incompleto & Dona de casa \\
P02 & 41 anos & F & Ensino Médio Completo & Agente de saúde \\
P03 & 32 anos & F & Ensino Superior Incompleto & Agricultora Rural \\
P04 & 65 anos & F & Pós-graduação & Educadora \\
P05 & 41 anos & F & Ensino Superior Completo & Professora \\
P06 & 43 anos & F & Ensino Superior Incompleto & Desempregada \\
P07 & 34 anos & M & Ensino Superior Completo & Auxiliar Administrativo \\
P08 & 33 anos & F & Ensino Técnico Completo & Técnica de Enfermagem \\
P09 & 44 anos & F & Ensino Médio Completo & Dona de casa \\
P10 & 31 anos & F & Ensino Médio Completo & Caixa
\end{tabular}

\section{INSTRUMENTO E PROCEDIMENTO DE COLETA DOS DADOS}

0 instrumento utilizado foi um protocolo de eliciamento de verbalização da conversa interna com base na "História do Patinho Feio". Trata-se de uma fábula, publicada pela primeira vez em 1843 por Hans Christian Andersen, adaptada por autor desconhecido para uso em dinâmicas de grupo com obesos e crianças. A coleta dos dados ocorreu em uma sala do Hospital Universitário de Vitória/ES onde a aparelhagem de vídeo havia sido montada previamente e o instrumento foi aplicado individualmente. A leitura da história pela pesquisadora era seguida da instrução: "Agora quero que você, sozinho na sala, 'pense em voz alta' sobre o que a história te fez pensar a respeito de você. Pode falar tudo que lhe vier na cabeça do jeito que vier, lembrando que não existem respostas certas ou erradas, e que não precisa 'falar bonito'". Durante a leitura, o visor da câmera ficava voltado para o participante, a fim de que o mesmo pudesse ir se habituando à câmera ligada. Após a instrução, a pesquisadora saía da sala, pedindo que o participante a chamasse ao término do vídeo. 0 tempo médio de gravação ficou em torno de 20 minutos. 0 recurso da câmara de vídeo já foi indicado na literatura científica como um eliciador de processos autoconscientes (Silvia \& Phillips, 2013). Os participantes que concordaram em participar da pesquisa receberam todos os esclarecimentos solicitados e assinaram o Termo de Consentimento Livre e Esclarecido."O presente estudo foi aprovado pelo Comitê de Ética da Centro de Ciências Humanas e Naturais da Universidade Federal do Espírito Santo, CAEE N.07469312.2.000.5542. 


\section{-4: INTERACÃO EM LF PSICOLOGIA}

\section{ANÁLISE DOS DADOS}

As verbalizações gravadas em vídeo foram transcritas na íntegra e submetidas a uma análise qualitativa fenomenológico-semiótica (Lanigan, 1992), cujo ponto de partida foi a epochè fenomenológica. Isto é, uma suspensão, por parte do pesquisador, de todo o conhecimento prévio que tem do fenômeno a ser investigado. Nesse momento, o pesquisador "coloca entre parênteses" todas as suas preconcepções a respeito daquilo que é o seu objeto de estudo. Este método consistiu inicialmente na demarcação de unidades de sentido nas transcrições das entrevistas dos participantes separadamente. Em seguida, o conjunto formado pelas unidades de sentido (ao longo das 10 transcrições) é reorganizado e separado em partes, constituindo novas unidades de sentido, agora representando a percepção dos indivíduos obesos enquanto um todo, etapa denominada como descrição. Uma mesma fala pode compor mais de uma unidade de sentido, contudo, o contexto no qual ela está inserida determina o significado único que especifica a unidade de sentido. Posteriormente, uma síntese agrupa as partes separadas em novos grupos que unem as unidades de sentido, em uma redução radical (etapa denominada redução), que em seguida, são acrescentadas a um todo para compor a interpretação (Gomes, 1998). A síntese da redução fenomenológica redefine a compreensão inicial do pesquisador, ao comparar e contrastar as unidades de sentido codificadas, com o objetivo de revelar a estrutura lógica que organiza tais unidades tematizadas na descrição. Na última etapa, a interpretação fenomenológica, a percepção do pesquisador é mesclada à percepção dos adultos obesos de sua experiência vivida e contrastada com outras percepções fornecidas pela literatura científica na área. Na perspectiva da fenomenologia-semiótica (Lanigan, 1992), o foco preferencial é a estrutura semiótica que organiza a percepção do fenômeno, devendo o pesquisador, desde a descrição, dirigir a análise para o contraste entre o todo expresso nas temáticas que abrangem as unidades de sentido e as partes expressas em falas individuais dos participantes. Desta forma, falas individuais são apresentadas como exemplares que ilustram o sentido das temáticas, completando uma relação do tipo figura-fundo, na qual uma ou qualquer parte é representativa do todo e o todo deve representar as qualidades de qualquer das partes. A lógica da análise fenomenológico-semiótica prioriza o fluxo da estrutura semiótica e não o fluxo da percepção individual dos participantes.

\section{RESULTADOS}

A apresentação dos resultados abrange, neste estudo, a descrição e a redução fenomenológicas. Enquanto a descri- ção aprofunda o contexto temático, a redução fenomenológica sinaliza o foco do sentido essencial que estrutura o fenômeno.

\section{DESCRIÇÃO FENOMENOLÓGICA}

0 processo reflexivo consciente dos adultos obesos candidatos à cirurgia bariátrica revelou 12 diferentes temas: (1) "Olhar-se no espelho", (2) "Aceitação", (3) "Ser diferente", (4) "Vergonha", (5) "Não sou o patinho feio", (6) "Discriminação", (7) "Crescimento pela dor", (8) "Limitações e superação", (9) "Mudança e resistência", (10) "Pensar mais nos outros do que em si", (11) "Opinião de terceiros" e (12) "Conceito de beleza". Todos os temas emergiram da análise da verbalização da conversa interna dos participantes e são descritos a seguir, acompanhados de uma fala ilustrativa, indicando entre parêntesis o código do participante e sua idade.

Tema (1). "Olhar-se no espelho" aparece como uma ação de autoconhecimento e percepção de si, tanto de forma direta, quando relacionada a autoconhecimento e autoaceitação após olhar-se no espelho e em fotos, quanto de forma indireta, quando os participantes relacionam o momento em que o patinho feio se conhece como cisne ao fato de ver sua imagem refletida no lago. Olhar-se no espelho revela-se também como uma expectativa positiva, ligada a um desejo de se perceber com aparência agradável após a cirurgia.

"Eu quero me olhar no espelho e quero me achar bonita" (P02 - 41a).

Tema (2). O tema "aceitação" abrange sentidos relacionados à aceitação de si próprio, bem como à necessidade de outras pessoas os aceitarem como obesos, e aponta para um sentimento que o obeso tem da não-aceitação do outro para com ele. Faz-se uma analogia entre a história da própria vida e a história do patinho feio para expressar o quanto o obeso não é aceito pela sociedade magra e, por vezes, nem mesmo pelo círculo familiar.

"O que me chamou atenção também é que nem a mãe aceitou o patinho do jeito que ele era." (P09 - 44a)

"A partir desse dia eu me aceitei como sou, gordo, com meus problemas, com minhas alegrias (...)" (P07 - 34a)

Tema (3). "Ser diferente" abrange as falas que referem um sentimento de não ser como as pessoas dentro do padrão do peso ideal, ou da maioria das pessoas. 0 tema se relaciona também à questão racial.

"[eu me sinto] ...como um patinho feio mesmo, no meio de um monte de patinho bonito (...) as pessoas olham de forma diferente, como se eu fosse diferente de todo mundo, como se eu fosse um peixe fora d'água..." (P10 - 31a) 


\section{MI* INTERACÃO EM LF PSICOLOGIA}

Tema (4). A "vergonha" abrange relatos de vergonha do próprio corpo, bem como do sentimento de não ter vergonha de ser como é. A expressão do sentimento de não ter vergonha é acompanhada por um reconhecimento das próprias qualidades pessoais, motivo de orgulho de si, tais como ter um rosto bonito, ser inteligente, simpático, engraçado, gostar de si e ser interessante.

"Não tinha mais vergonha do meu corpo, comecei a me achar interessante, bonito, independente das diferenças." (P07 - 34a).

Tema (5). "Não sou o patinho feio" abrange os relatos que buscam afirmar uma diferenciação do personagem principal da história, embora acompanhada de um reconhecimento de que a identificação com o patinho feio já ocorreu em algum momento. Tal diferenciação é atribuída tanto a uma mudança interna, quanto a uma contingência do ambiente.

“(...) eu não sou mais o patinho feio, mas por muito tempo eu já fui (...) E ser um cisne lindo, um deus grego como alguns dizem, está muito próximo." (P07 - 34a).

"Eu sinceramente não sou uma patinha feia! Mas poderia ter sido se eu não tivesse encontrado uma família pra me criar." (P04 - 65a).

Tema (6). A "discriminação" se refere tanto à descrição de situações que abrangeram sofrimento físico e psíquico experienciado pelo personagem principal da história, quanto a situações caracterizadas como discriminação contra o participante obeso, envolvendo agressões verbais e maus tratos. Esses relatos são acompanhados de sentimentos de esgotamento. 0 processo reflexivo expresso na conversa interna sugere uma identificação com a história do patinho feio, a ponto de as duas histórias (a própria e a do patinho) confundirem-se, por vezes, em uma só narrativa.

"Apanhou muito, foi muito bicado, muito massacrado pelas galinhas, pelos amig (sic)... pelos próprios... amig (sic)... patinhos." (P01 - 52a).

"[o filho] era agredido pelos amigos na escola por causa de mim." (...) “'Ah, usa o seu banheiro! Meu vaso não suporta você.' Já ouvi muito isso. Eu já não aguento mais essa situação." (P08 - 33a).

Tema (7). O "crescimento pelo dor" abrange relatos de novos comportamentos aprendidos após experiências de discriminação, ofensas e sofrimentos. Eles descrevem atitudes antes e após as experiências de discriminação. Tais relatos são acompanhados de um sentimento de descaso e/ou despreocupação com a opinião alheia.

"[As situações em que] a gente toma na cara (sic)... fazem
Petra Paim Ehrenbrink e Mariane Lima de Souza

a gente crescer um pouco" (P03 - 32a).

Tema (8). As "limitações e superação" incluem tanto descrições de atividades simples do cotidiano que foram deixadas de fazer por conta da obesidade, como comprar roupas e usar o transporte público; quanto situações mais complexas, como conseguir um emprego melhor e privar-se do convívio social. As limitações são seguidas de um desejo de superação, indicado por uma forma de vida que os participantes gostariam de ter e acreditam que terão após a cirurgia.

"Eu quero viver assim, saudavelmente, quero poder tá (sic) fazendo uma caminhada, quero poder sair, dançar, fazer essas coisas que eu gosto de fazer." (P02 - 41a).

Tema (9). "Mudança e resistência” envolve a expressão de um desejo de mudança que não é uma transformação radical, em algo já perfeito, mas sim um processo em andamento. Ao mesmo tempo em que implica uma identificação com o patinho feio, também implica uma rejeição a "tornar-se um cisne", isto é, a ter de se ajustar a padrões estéticos, tornando-se um modelo de beleza. Ao invés disso, a mudança refere-se a questões de valor ético, como tornar-se uma pessoa mais saudável, melhor e mais bem resolvida consigo mesmo.

“Eu não quero virar um cisne, mas quero ser uma pessoa melhor!” (P08 - 33a).

Tema (10). "Pensar mais nos outros do que em si" inclui descrições de atitudes de preocupação com o outro mais, inclusive, do que consigo próprio como, por exemplo, não cuidar de si para cuidar do outro, deixar de resolver seus próprios problemas para resolver o dos outros, e se privar de atividades que gostaria de fazer por conta de terceiros. São relatos acompanhados de sentimentos negativos por não estar tendo tempo o suficiente de cuidar de si.

"Porque eu me preocupo tanto com as coisas dos outros do que com meus próprios [problemas], que eles acabam esquecidos, empurrados com a barriga" (P03-32a).

Tema (11). A "opinião de terceiros" descreve a percepção que os participantes têm sobre o que os outros pensam sobre eles e se relaciona especialmente às situações em que o participante é julgado e criticado por conta de sua obesidade. Esse tema abrange as verbalizações nas quais o participante coloca-se no lugar do outro e simula a sua fala e a sua voz.

" 'Você tá (sic) gorda! Você tá (sic) fazendo dieta? Quantos quilos você já emagreceu?' Eu não tenho que dar satisfação da minha vida pra ninguém! Eu não preciso disso!" (P05 - 41a)

Tema (12). o conceito de beleza é definido a partir da oposição interior/exterior. A beleza exterior é a uma beleza fí- 


\section{INTERACÃO EM LF PSICOLOGIA}

sica, definida como a que é importante para o "público", isto é, aquilo que é visível aos outros. A beleza interior é aquela que não é visível diretamente, envolve as qualidades pessoais "além do corpo".

"Eu sei que o que importa hoje para o público, pras pessoas que vivem à nossa volta é a aparência e não a beleza que a gente tem por dentro, essa beleza que eu tenho por dentro minha." (P03 - 32a)

\section{REDUÇÃO FENOMENOLÓGICA}

A redução fenomenológica identificou dois pontos principais, compondo um foco problemático que permeia todos os temas explicitados na descrição: o "eu como obeso que aceita a própria condição" em oposição ao "eu como obeso que precisa se adaptar a uma sociedade magra". O pólo da aceitação revela uma autoconsciência positiva do participante relacionada à experiência de aceitar-se como obeso, não sentir vergonha do que se é e de como se é, não se identificar com o patinho feio enquanto metáfora de um sentimento de autodepreciação e autodesvalorização. O "eu como obeso que aceita a própria condição" associa-se, ainda, a uma percepção e valorização de aspectos pessoais não relacionados a conceitos de beleza, a uma satisfação com as próprias características pessoais. Associa-se também a um autoconhecimento das estratégias de enfrentamento da obesidade e de situações de discriminação.

O "eu como obeso que precisa se adaptar a uma sociedade magra" expressa uma percepção da dificuldade de ser obeso em uma sociedade planejada para pessoas magras e aparece relacionado à experiência de vivenciar limitações, discriminação e desejo de mudança, de achar-se feio, de se sentir diferente das outras pessoas e de identificação com a história do patinho feio. 0 pólo da necessidade de adaptação associa-se a uma sensibilidade à opinião de terceiros e a um processo reflexivo que tem como foco prioritário o outro e não a si próprio.

\section{DISCUSSÃO}

\section{INTERPRETAÇÃO FENOMENOLÓGICA}

As temáticas de conversa interna dos obesos serão discutidas, a seguir, agrupadas de acordo com as aproximações significativas entre as mesmas e não, exatamente, na ordem em que foram apresentadas na descrição fenomenológica. 0 ponto de partida é o Tema (1).

"Olhar-se no espelho", como também em fotografias, é um artifício que facilita a autopercepção. No caso dos adultos obesos à espera de cirurgia bariátrica, essa temática da sua conversação interna parece sugerir, contudo, que tomar cons-
Petra Paim Ehrenbrink e Mariane Lima de Souza

ciência de si não é uma experiência tão natural e intuitiva como vivenciada pelas pessoas cotidianamente. Pode-se supor que, para os participantes da pesquisa, autopercepção corporal e autoconsciência são, ao mesmo tempo, processos estreitamente vinculados entre si, e independentes. Isto é, a autopercepção corporal parece ser subtraída do processo reflexivo, até o limite da percepção visual. De fato, um estudo de caso sobre o uso da arte no reconhecimento do corpo analisou a experiência de uma jovem em preparação psicológica para a cirurgia bariátrica, que passou a esculpir o próprio corpo em terracota (Gleiser, 2006). O estudo de caso aponta para a dificuldade de pacientes obesos em olharem-se adequadamente. Ações corriqueiras como tirar fotos e olhar-se no espelho são consideradas tarefas difíceis, como se ver a si próprio trouxesse uma dificuldade em aceitar a própria imagem associada à doença.

O tema da "aceitação" sugere, justamente, a experiência de ser um paciente com uma doença crônica, porém, com certa especificidade. Um estudo sobre adolescentes com diversas doenças crônicas (fibrose cística, cirrose hepática, diabete melito e febre reumática, contudo, não obesos) revelou que o processo de "tomar conhecimento da doença" é fundamental para a busca e adesão ao tratamento (Oliveira \& Gomes, 2004). No caso dos adultos obesos, não se trata de uma dificuldade de ter conhecimento da doença, uma vez que seu diagnóstico é fácil, por ser uma doença visível. A temática da "aceitação" na amostra dos adultos obesos parece indicar um processo reflexivo mais similar aos casos de uso de substâncias tóxicas, como álcool, nos quais o indivíduo, mais do que "tomar conhecimento", passa a aceitar sua condição (no caso, como obeso) para o início do tratamento ser viabilizado (Oliveira, 2009).

Outra diferença com relação às doenças crônicas é a participação dos familiares. No caso dos adolescentes com doenças crônicas, os familiares não só aceitam a doença como o ajudam no seu tratamento (Oliveira \& Gomes, 2004). 0 adulto obeso, ao contrário, revela uma percepção de si como alguém que não somente precisa lutar pela própria aceitação, como sofre com a falta de aceitação da doença pelos familiares e outras pessoas de seu meio social. 0 sentimento de falta de aceitação pelas outras pessoas aparece vinculado à experiência de ser socialmente pressionado para o tratamento da obesidade.

A pressão social aparece no tema "Opinião de terceiros" e caracteriza um processo reflexivo no qual a assimilação da perspectiva do outro em relação a si mesmo é o aspecto de grande relevância. Conforme Mead (1934/2015), a autoconsciência é tornar-se objeto para si mesmo, em virtude de relações do próprio sujeito com os outros. Trata-se de um olhar já internalizado do outro no lugar do eu, que olha para si como objeto. Contudo, no caso do adulto obeso, o outro aparece 


\section{H* INTERACÃO EM 4F PSICOLOGIA}

como a normalidade, estabelecendo uma oposição crítica importante, a partir da qual o obeso passa a se perceber como o diferente. Por conseguinte, "Opinião do outro" tem uma conotação afetiva negativa e se relaciona, por vezes, com o tema da "Discriminação".

A "Discriminação" como um tema do processo reflexivo expresso na conversa interna dos adultos obesos pode ser explicada pelo fato de que a obesidade é uma doença acompanhada por inúmeros estigmas (Goffman, 1998). É também uma doença observável publicamente, o que leva as pessoas a buscarem soluções para esconder ou modificar suas diferenças a fim de obter aceitação em ambientes sociais. Contudo, tal esforço causa, muitas vezes, sofrimento ao obeso.

O tema "Crescimento pela dor" emergiu, portanto, estreitamente vinculado tanto à discriminação quanto à opinião do outro. Refere-se a situações de vivências de discriminação, vinculadas à expressão de um sentimento de descaso com a opinião alheia. De fato, estudos sobre o bullying (Costa, Souza \& Oliveira, 2012; Louzada, Louzada \& Lazarini, 2008) relacionam o sentimento de descaso, ou de não se importar mais com a opinião de terceiros ao sentimento de cansaço. Isto é por já ter passado inúmeras vezes pela experiência de preconceito e discriminação, "lutar contra" torna-se um processo cansativo demais para o indivíduo.

Por outro lado, "Pensar mais no outro do que em si mesmo" revelou-se um aspecto fundamental da reflexividade dos participantes, de forma muito similar ao tema "Opinião de terceiros". Tal aspecto não é vivenciado como uma experiência positiva, mas sim negativa, possivelmente associada à autonegligência e à baixa autoestima, que está presente na experiência vivida do indivíduo obeso desde a infância (Silva et al., 2009), bem como à depressão em obesos (Moraes, Almeida, \& Souza, 2013).

O tema "Limitações e superação" apareceu justamente como um aspecto complementar da necessidade de se adaptar a uma sociedade magra. De acordo com Nóbrega (2011), a sociedade não está preparada para receber as pessoas obesas:

A sociedade foi projetada para o magro; o gordo está excluído. Percebe-se a rejeição explícita nas roupas, nos provadores de roupa das lojas, nas catracas dos ônibus, nas cadeiras de cinemas e teatros. Nos aviões é grotesca a exclusão: as cadeiras, o cinto de segurança, o banheiro, e a mesa de refeição não são compatíveis com as pessoas com o corpo além das curtas medidas do padrão social (p. 51).

Embora a obesidade seja um problema socialmente notado, o foco da conversa interna dos participantes pareceu centrar-se não exatamente no excesso de peso ou suas consequências (para sua saúde geral, por exemplo), mas, sim no fato de não poderem comprar roupas, andar de ônibus, entre outras coisas que as pessoas na faixa de peso considerada normal podem fazer. Portanto, pode-se entender que, na perspectiva dessa amostra, a cirurgia pode ser motivada mais por uma vontade de adaptação à sociedade magra, do que um desejo próprio de ser magro.

O tema "Mudança e resistência" relacionou-se a uma ambiguidade na autoconsciência do obeso de seu desejo de mudança. 0 desejo de mudança se expressa na conversa interna nas referências às atividades que gostariam de fazer e não podem devido ao peso, no desejo de se ver bem, bonito, saudável. Entretanto, o processo reflexivo evidenciado na conversa interna dos obesos não parece implicar necessariamente um sentimento radical de não-aceitação ou de autorrejeição que exija uma mudança radical, uma vez que se explicita ou uma recusa de identidade com o patinho feio, ou uma percepção de superação do sentimento de ser o diferente, aquele que não é aceito. Há uma referência à mudança, entretanto, essa mudança não significa o final de um processo, mas uma fase de transição. "Mudança e resistência" associaram-se também com uma mudança completa de identidade, como se o emagrecimento do corpo pudesse transformar a personalidade. Contudo, há a percepção de que não é possível mudar, ou de que essa mudança seria contra os próprios princípios.

De fato, um estudo sobre a realidade corporal e a construção do self na perspectiva do "construcionismo leve"1 (Barnard, 2000) explica o corpo como se tratando de uma construção psicológica originada, mantida e transformada através de uma intenção do self. Além disso, o corpo pode ser um limitador da construção do self. Portanto, o self seria pré-determinado por uma série de restrições já delimitadas pelo corpo, como por exemplo, o sexo - o self será construído a partir dos elementos dados biologicamente. Entretanto, nos dias de hoje temos a possibilidade de mudar nossa realidade corporal por meio de inúmeras cirurgias como, por exemplo, a cirurgia de mudança de sexo. Já é possível, atualmente, que um indivíduo nasça do sexo feminino, mas construa seu self de forma masculina, adaptando o corpo ao self.

Desta forma, o processo reflexivo parece abarcar, em toda a sua complexidade, uma tensão entre a mudança no corpo e a mudança de si. Isso pode ser explicado pelo fato de que não há identidade sem corporeidade, e corporeidade não é só um corpo, mesmo porque a primeira é um processo e o segundo é um objeto (Kolyniak, 2005). O processo da corporeidade pressupõe interações sociais, nas quais os corpos são socializados. A construção da corporeidade pressupõe a recíproca construção da identidade, de modo que uma se transformando, a outra é transformada. 


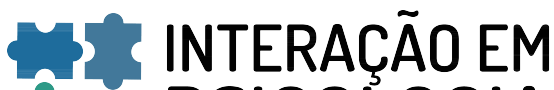 ET PSICOLOGIA}

O corpo hoje não é apenas uma parte do self, mas é um objeto social. O corpo como uma entidade comunicativa, capaz de transmitir mensagens através de gestos - não é apenas uma entidade orgânica, mas um evento social, cultural, religioso e psicológico. 0 corpo e a imagem do corpo ocupam lugar central na vida do homem moderno e em sua relação com o mundo e seus pares (Veiga, 2006).

Neste sentido, o tema "Conceito de beleza" que valoriza uma beleza interna e não externa surge como solução para o desencontro entre a percepção que o obeso tem de seu corpo e os padrões de beleza socialmente prescritos atualmente. Um estudo sobre fatores biopsicossociais envolvidos na decisão de realização da cirurgia bariátrica sugere que fatores estéticos não são raros como motivadores na busca pela cirurgia, e esses são justificados pelos obesos serem estigmatizados socialmente (Moliner \& Rabuske, 2008). Conforme o estudo, a estética aparece relacionada à autoestima e a sentimentos de valorização ou desvalorização que a pessoa desenvolveu a respeito de si mesma devido ao sobrepeso.

De forma geral, a análise qualitativa dos conteúdos da conversa interna realizada nesta pesquisa possibilitou um entendimento mais detalhado da percepção do obeso à espera da cirurgia bariátrica de sua condição, isto é, de seu processo reflexivo. Entretanto, os achados também sugeriram uma dificuldade metodológica relacionada ao procedimento de acessar mais diretamente a conversa interna, já apontada na literatura científica em estudos relacionados ao tema (conferir especialmente Morin, 2012). Tal dificuldade pode ser contornada em estudos futuros, por exemplo, com um procedimento metodológico que permita a comparação entre o registro da conversa interna de participantes previamente treinados para falarem diante de uma câmera e outros não treinados para a filmagem. É importante observar, ainda, que o procedimento metodológico de eliciamento da conversa interna foi efetivo e parece ter apresentado ganhos para o próprio participante em termos de auto-observação, autopercepção e de processamento mais eficiente de algumas informações. Durante o procedimento, foi comum o relato de insights pelos participantes, isto é, a verbalização de que estavam pensando e compreendendo o assunto em questão pela primeira vez. Tais relatos podem ser indicadores de uma nova tomada de perspectiva sobre si, que pode levar a uma autopercepção mais ampliada.

Por fim, os achados desse estudo permitiram, ainda, uma observação importante sobre o tema da discriminação expresso na conversa interna dos adultos obesos candidatos à cirurgia bariátrica. Ele revelou-se diferente do vivenciado em outras populações que sofrem com discriminação e lutam para serem aceitos, como por exemplo, os homossexuais, ou mesmo os obesos que optam por não emagrecer, uma vez que os candidatos à cirurgia bariátrica buscam eliminar, ao invés de afirmar, a característica percebida como "diferente", em um esforço para se enquadrarem à sociedade que os discrimina. Portanto, psicólogos e outros profissionais da área de saúde que tem contato com essa população devem estar atentos a essas peculiaridades do funcionamento do processo reflexivo desses pacientes para melhor direcionar o seu trabalho na prática clínica.

\section{CONTRIBUIÇÃO DE CADA AUTOR}

P.P.E. e M.L.S. foram responsáveis pela conceitualização; P.P.E. pela investigação e redação e M.L.S pela redação final, edição e supervisão.

\section{DECLARAÇÃO DE CONFLITOS DE INTERESSES}

Os autores declaram que não há conflitos de interesse neste artigo.

\section{DECLARAÇÃO DE FINANCIAMENTO}

A pesquisa foi financiada parcialmente pela bolsa de mestrado da primeira autora (CAPES).

\section{REFERÊNCIAS}

Archer, M. S. (2012). The reflexive imperative in late modernity. Cambridge: Cambridge University Press.

Bahia, L.R., \& Araújo, D.V. (2014). Impacto econômico da obesidade do Brasil. Revista HUPE, 13, 13-17. http://dx.doi.org/10.12957/rhupe.2014.9793

Barnard, S. (2000). Construction and corporeality: Theoretical psychology and biomedical technologies of the self. Theory \& Psychology, 10 (5), 669-688. https://doi.org/ $10.1177 / 0959354300105005$

Benites, D., Gauer, G., \& Gomes, W. B. (2016). Personal journal blogs as manifest internal conversation toward self-innovation: A semiotic phenomenological analysis. Estudos de Psicologia, 33 (3), 431-442. http://dx.doi.org/ 10.1590/1982-02752016000300007

Cataneo, C., Carvalho, A. M. P., \& Galindo, E. M. C. (2005). Obesidade e aspectos psicológicos: Maturidade emocional, auto-conceito, lócus de controle e ansiedade. Psicologia: Reflexão e Crítica, 18(1), 39-46. https://doi.org/ $10.1590 / \mathrm{s} 0102-79722005000100006$

Creswell, J. W., \& Clark, V. L. P. (2013). Pesquisa de métodos mistos. ( $2^{\mathrm{a}}$ ed). Porto Alegre: Editora Penso.

Costa, M. A. P, Souza, M. A., \& Oliveira, V. M. (2012). Obesidade infantil e bullying: A ótica dos professores. Educação e Pesquisa, 38(3), 653-665. https://doi.org/10.1590/s151797022012005000017 


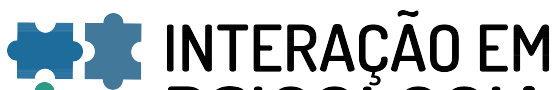 ET PSICOLOGIA}

Da Silveira, A.C., De Souza, M. L., \& Gomes, W. B. (2010). “Falar com meus botões": Pelos meandros teóricos e empíricos das relações entre conversa interna, reflexividade e self. Estudos de Psicologia, 15(3), 223-231. https://doi.org/ $10.1590 / \mathrm{s} 1413-294 \times 2010000300001$

Da Silveira, A., De Souza, M. L., \& Gomes, W. B. (2015). Selfconsciousness concept and assessment in self-report measures. Frontiers in Psychology, 6(930), 1-11. https:// doi.org/10.3389/fpsyg.2015.00930

Franques, A. R. M. (2002). Participação do psiquiatra e do psicólogo na fase perioperatória: Participação do psicólogo. Em: A. B. Garrido (Org.), Cirurgia da obesidade (pp. 75-79). São Paulo: Editora Atheneu.

Gleiser, D. (2006). Avaliação pré-operatória de uma paciente artista visual: 0 uso da arte no reconhecimento do corpo. Em: A. R. M. Franques. \&, M. S. Arenales-Loli (Orgs.) Contribuições da psicologia na cirurgia da obesidade (pp.7582). São Paulo: Vetor.

Goffman, E. (1998). Estigma - Notas sobre a manipulação da identidade deterioriada. (M. B. M. L. Nunes, Trad.). Rio de Janeiro: Guanabara.

Gomes, W. B. (Org). (1998). Fenomenologia e pesquisa em psicologia. Porto Alegre: Editora da Universidade Federal do Rio Grande do Sul.

Kolyniak, H. M. R. (2005). Identificar-se com uma nova corporeidade. Em: F. C. G Santos. (Org.). Magro, e agora? História de obesos mórbidos que se submeteram à cirurgia bariátrica (pp. 19-21). São Paulo: Vetor.

Lanigan, R. (1992). The human science of communicology. Pittsburgh: Duquesne University Press.

Louzada, S. S. S., Louzada, G. L. S., \& Lazarani, Z. B. S. (2008). 0 bullying na vida dos adolescentes. Revista FACEVV, 1, 76-84.

Mead, G. H. (2015). Mind, self, and society: The definitive edition. E-livro. Chicago: University of Chicago Press. (Obra original publicada em inglês em 1934).

Moliner, J. de, \& Rabuske, M. M. (2008). Fatores biopsicossociais envolvidos na decisão de realização da cirurgia bariátrica. Revista Psicologia: Teoria e Prática, 10(2), 44-60.

Moraes, P. M., \& Dias, C. M. S. B. (2012). Obesidade infantil a partir de um olhar histórico sobre alimentação. Interação em Psicologia, 16 (2), 317-326. https://doi.org/10.5380/ psi.v16i2.21755

Moraes, A. L., Almeida, E. C., \& Souza, L. B. (2013). Percepções de obesos deprimidos sobre os fatores envolvidos na manutenção da sua obesidade: Investigação numa unidade do Programa Saúde da Família no município do Rio de Janeiro. Physis: Revista de Saúde Coletiva, 23 (2), 553572. 73312013000200012
Morin, A. (2012). Inner speech. In W. Hirstein (Ed.). Encyclopedia of Human Behavior (pp. 436-443) (2nd Ed.). Amsterdam: $\quad$ Elsevier. https://doi.org/10.1016/ B978-0-12-375000-6.00206-8

Morin, A. (2017). Toward a glossary of self-related terms. Frontiers in Psychology, 8, Artigo 280. https://doi.org/ 10.3389/fpsyg.2017.00280

Motta, F. E., Rafalski, J. C., Rangel, I. C., \& Souza, M. L. de. (2013). Narrative and dialogical reflexivity: An approach between writing and inner speech. Psicologia: Reflexão e Crítica, 26, 609-616. https://doi.org/10.1590/s010279722013000300021

Nóbrega, G. (2011). Obesidade, cirurgia bariátrica e emagrecimento, vivências e significados. Curitiba: Juruá.

Oliveira, B. P. (2009). Alcoolismo: Vivência familiar de uma doença social. Dissertação de Mestrado, Faculdade de Letras da Universidade do Porto, Porto.

Oliveira, V. Z., \& Gomes, W. B. (2004). Comunicação médicopaciente e adesão ao tratamento em adolescentes portadores de doenças orgânicas crônicas. Estudos de Psicologia, 9, 459-469. https://doi.org/10.1590/ s1413-294x2004000300008

Oliveira, J. H. A., \& Yoshida, E. M. P. (2009). Aspectos psicológicos de obesos grau III antes e depois de cirurgia bariátrica. Psicologia: Reflexão e Crítica, 22, 1-8. https://doi.org/ 10.1590/s0102-79722009000100003

Organização Mundial da Saúde (2016). Obesity and Overweight. Recuperado em 11 de novembro de 2016 de <http://www.who.int/mediacentre/factsheets/fs311/en/>

Silva, D., Rego, C. M., Valente, A., Faria, M., Dias, C., Azevedo, L. F., Martins, C., \& Guerra, A. (2009). Avaliação da insatisfação corporal e da auto-estima em crianças e adolescentes com diagnóstico de obesidade vs uma comunidade escolar. Revista Portuguesa de Endocrinologia, Diabetes e Metabolismo, 1, 23-31.

Silvia, P. J., \& Phillips, A. G. (2013). Self-awareness without awareness? Implicit self-focused attention and behavioral self-regulation. Self Identity, 12 (2), 114-127. https:// doi.org/10.1080/15298868.2011.639550

Travado, L., Pires, R., Martins, V., Ventura, C., \& Cunha, S. (2004). Abordagem psicológica da obesidade mórbida: Caracterização e apresentação do protocolo de avaliação psicológica. Análise Psicológica, 3(XXII), 533-550. https:// doi.org/10.14417/ap.225

Veiga, A. P. (2006). A institucionalização da beleza no universo feminino. IGT na Rede, 3(5), 1-9.

Recebido: em 04/06/2017 Primeira decisão editorial em: 09/09/2017 Aceito em: 18/10/2017

\footnotetext{
1 Tradução nossa para "light constructionism", em inglês, no original (Barnard, 2000, p. 682).
} 